\title{
RESISTANCE COILS FOR ALTERNATING CURRENT WORK
}

\author{
By H. L. Curtis and F. W. Grover
}

\section{CONTENTS}

I. Introduction ....................................... Page.

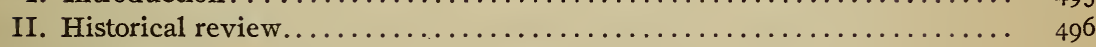

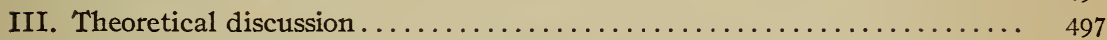

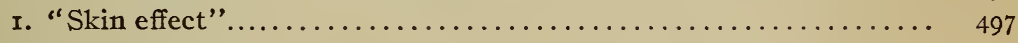

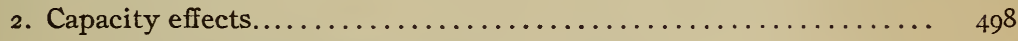

(a) Effect of temperature upon the capacity ............... 502

(b) Effect of humidity upon the capacity................. 502

3. Effect of absorption in the dielectric between the wires.......... 503

4. Conclusions from theoretical work..................... 505

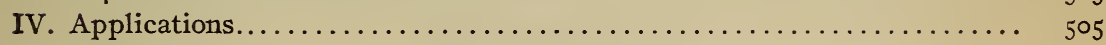

I. Hundred-ohm coils.................................... 507

2. Ten-ohm coils....................................... 507

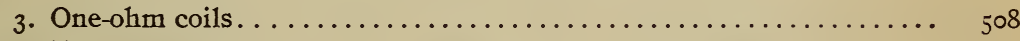

4. Tenth-ohm coils................................... 509

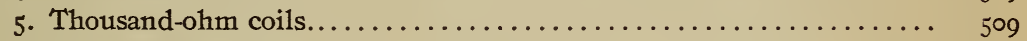

6. Five-thousand-ohm coils............................ $5^{\text {II }}$

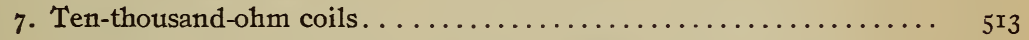

8. Comparison of new coils with ordinary "noninductive" coils...... $5^{\mathrm{r} 3}$

9. Methods of connecting coils in boxes................... $5^{\mathrm{I} 4}$

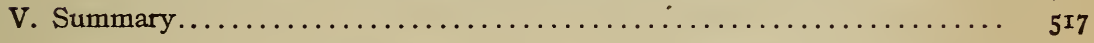

\section{INTRODUCTION}

The increase in the precision demanded in alternating-current work has made desirable an investigation into the behavior of resistance coils when subjected to an alternating-current voltage. As many of the commercial coils which give excellent results with direct currents have in the course of these experiments been found to be quite unsatisfactory for alternating-current measurements, specifications have been prepared for the construction of coils which will be suitable for this kind of work. The range of resistances covered is from o.I to Ioooo ohms, though in most cases 
only coils whose resistance is a power of ro have been studied. The range of frequencies covered is from o to 3000 cycles, though the greater part of the work has been done in the interval from I 200 to 500 cycles.

In an ideal resistance coil for alternating-current work two requirements need to be fulfilled, (I) the resistance must be independent of the frequency and (2) the phase angle must be zero. The design of coils which will fulfill these conditions as nearly as possible presents several interesting problems and the solution in any given case will depend upon the magnitude of the resistance of the coil. In order that some of the difficulties may be appreciated, a theoretical discussion of the factors which must be considered in the design of such a coil will be given. This will be followed by a description of the designs which have been found satisfactory, together with some suggestions as to proper methods of connecting the coils when they are to be used in a resistance box.

\section{HISTORICAL}

Some work along the lines indicated has already been done. When Kohlrausch began to make ${ }^{1}$ alternating-current measurements, he found that the coils which were in use at that time were not satisfactory. In his later work ${ }^{2}$ he avoided the use of coils larger than 2000 ohms. He attributed the difficulty with the larger-valued coils to capacity between the windings. Acting on this suggestion Chaperon ${ }^{3}$ devised his well known winding. This consists in winding each layer inductively, but reversing the direction of winding of alternate layers, and thus necessitates a multiple-layer coil. This construction reduces the capacity without increasing the inductance materially. A slight improvement was claimed by Cauro ${ }^{4}$ who carried the wire back across the coil, thus starting each layer at the same point but winding alternate layers in opposite directions.

A different method of making a high resistance with small effective inductance is due to Rowland, ${ }^{5}$ who wound a fine wire inductively on a thin sheet of mica. While not of a convenient

\footnotetext{
1 Pogg. Ann., 138, p. 280; 1869.

${ }^{2}$ Ann. d. Phys., 26, p. 16r; 1885 .

${ }^{3}$ Comptes Rendus, 108 , p. 799; 1889 .
} 
form for some kinds of work, such resistances have been extensively used in the multipliers of voltmeters and wattmeters. Recently Orlich ${ }^{6}$ has designed resistances in which the time constant (according to an approximate calculation) is zero. It consists of an inductive winding on a slab of slate, with a second winding held at the calculated distance outside of this by caps on the ends of the slab. In this way he obtained a time constant of $4 \times 10^{-7}$ second with a coil of 25000 ohms.

The above work was all done with high resistances. Within a few years there has been a demand for low resistances having a small time constant for use as shunts to alternating-current ammeters. Campbell, ${ }^{7}$ Orlich, ${ }^{8}$ and Drysdale ${ }^{9}$ have each designed resistances for this purpose. A consideration of these lies outside the purpose of this paper.

Some measurements of the effective inductance of commercial coils have been made by Taylor and Williams ${ }^{10}$ and by Brown. ${ }^{11}$ They did not, however, attempt to improve the design of coils.

\section{THEORETICAL}

It has already been stated that in an ideal resistance coil for alternating-current work the phase angle should be sensibly zero and the change of resistance with frequency negligible. The most obvious thing to do to make the phase angle small is to wind the coil in such a way that its inductance will be a minimum. However, there are three other factors which need to be considered in a discussion of the phase angle, viz: (I) "Skin effect," (2) capacity in parallel with the resistance, and (3) absorption in the dielectric between the wires. Each gives rise, also, to a change in the effective resistance of the coil. It is the purpose of the following theoretical investigation to show how each of these three factors enters and to give an idea of the magnitude of the effects which they produce.

\section{1. "SKIN EFFECT"}

The resistance of a conductor for alternating current is greater than for direct current, because in the former case the current

6 Verh. d. Deut. Phys. Ges., 12, p. 949; 1910.

7 Electrician, 61, p. I000; 1908.

${ }^{8}$ Zs. für Instrk., 29, p. 24r; 1909.
${ }^{9}$ Electrician, 66, p. 34I; I9Iо.

${ }_{10}$ Phys. Rev., 26, p. 4I7; I908.

11 Phys. Rev., 29, p. 369; I909. 
density is greater near the outside of the conductor than near its center. On the other hand, this change in current distribution with the frequency decreases the inductance, though the relative change is much less than the change in the resistance. In the case of a circuit containing only resistance and inductance $\tan \theta=p L / R$ where $\theta$ is the phase angle, $p$ is $2 \pi$ times the frequency, $L$ the self-induction and $R$ the resistance. Hence, if the change in $R$, due to skin effect, can be shown to be negligible, the effect upon the phase angle will also be negligible.

Formulas ${ }^{12}$ have been compiled by which the change of resistance with frequency can be computed in the case of a straight cylindrical wire. If now this wire is wound on a spool, or put in any shape such that its total inductance is increased, then its change of resistance will be increased; but if it is so wound that its inductance is decreased, then the change of resistance will be decreased. As the latter form is always used in resistance coils, a maximum value of the change in resistance may be found by computing the case of a straight wire.

For a manganin wire the formula shows that with 3000 cycles the diameter must be as large as $2 \mathrm{~mm}$ before the skin effect produces a change of I part in roo ooo. All of the wires used in this investigation are much smaller than this. The computed resistance change for the largest wire used $(0.24 \mathrm{~mm})$ is only I part in ${ }^{2} \mathrm{O}^{9}$. In some of the smaller-valued coils strip manganin of o.I mm thickness has been used. Computing by the formula of Bethenod ${ }^{13}$ the resistance change in this case is also found to be negligible.

Hence, in none of the coils which we have designed will the skin effect be appreciable. In fact, it may be said that the resistance of most commercial coils having a resistance of $\mathrm{I}$ ohm or over is not affected by the skin effect up to 3000 cycles.

\section{CAPACITY EFFECTS}

In a resistance coil it is often necessary to consider not only the resistance and inductance of the conductor, but also the electrostatic capacity between the different parts of the conductor. To

12 Rosa and Grover, this Bulletin, 8, p. I72; I911. Reprint No. 169.

${ }^{13} \mathrm{Jahrb}$. d. drath. Telegraphie, 2, p. 397; 1909. 
show this effect in a simple case, consider a coil (Fig. I) having a resistance $R$ and inductance $L$ which is in parallel with a condenser of capacity $C$. Then the impedance of the upper circuit is $R+i p L$ and of the lower is $-\frac{i}{p C}=\frac{\mathrm{I}}{i p C}$. Then if $A$ is the impedance of the two circuits in parallel

$$
\begin{aligned}
& \frac{\mathrm{I}}{A}=\frac{\mathrm{I}}{R+i p L}+i p C=\frac{\mathrm{I}-p^{2} C L+i p C R}{R+i p L} \\
& A=\frac{R+i p L}{\mathrm{I}-p^{2} C L+i p C R}=\frac{R+i p\left(L-C R^{2}-p^{2} C L^{2}\right)}{\left(\mathrm{I}-p^{2} C L\right)^{2}+p^{2} C^{2} R^{2}}
\end{aligned}
$$

or

We may write $A=R^{\prime}+i p L^{\prime}$ where $R^{\prime}$ and $L^{\prime}$ are, respectively, the effective resistance and effective inductance of the system. Then by separating real and imaginary parts

$$
R^{\prime}=\frac{R}{\mathrm{I}-p^{2} C\left(2 L-C R^{2}\right)+p^{4} C^{2} L^{2}}
$$

and

$$
L^{\prime}=\frac{L-C R^{2}-p^{2} C L^{2}}{\mathrm{I}-p^{2} C\left(2 L-C R^{2}\right)+p^{4} C^{2} L^{2}}
$$

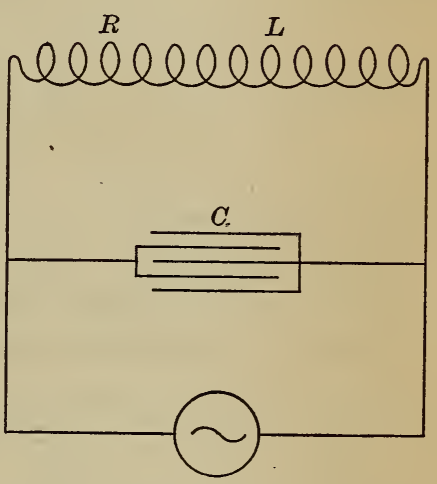

The phase angle $\theta=\tan ^{-1} \frac{p L^{\prime}}{R^{\prime}}$

Fig. 1.-Diagram to Show a Capacity in Paraliel with a Coil which has Resistance and Inductance

$$
=\tan ^{-1} p \frac{\left(L-C R^{2}-p^{2} C L^{2}\right)}{R}
$$

If we make a first approximation assuming both $L$ and $C$ small, we have

$$
\begin{aligned}
R^{\prime} & =R\left[\mathrm{I}+p^{2} C\left(2 L-C R^{2}\right)\right] \\
L^{\prime} & =L-C R^{2} \\
\tan \theta & =\frac{p\left(L-C R^{2}\right)}{R}
\end{aligned}
$$

It should be noted that the phase angle will be zero if $L-C R^{2}=0$, but that the change in resistance will be zero if $C=0$, or if 
$2 L-C R^{2}=0$. Hence, both the phase angle and the change of resistance will be zero only under the condition that $C=0$ and $L=\mathrm{O}$.

If we consider the case of two parallel wires, the capacity is distributed, so that the effect is not the same as that given above. The solution in this case requires the integration of the differential equations ${ }^{14}$ which express the emf and current at each point of the line at each instant. This solution gives, as a first approximation,

$$
\begin{aligned}
R^{\prime} & =R\left[\mathrm{I}+p^{2} C\left(\frac{\mathrm{I}}{3} L-\frac{2}{\mathrm{I} 5} C R^{2}\right)\right] \\
L^{\prime} & =L-\frac{\mathrm{I}}{3} C R^{2} \\
\tan \theta & =p \frac{\left(L-\frac{\mathrm{I}}{3} C R^{2}\right)}{R}
\end{aligned}
$$

Where $R, C$, and $L$ are the total resistance, capacity, and inductance of the wires.

Again, it will be seen that an ideal coil is only possible, provided $C$ and $L$ are both zero. However, if $C$ is small and if $L-\frac{I}{3} C R^{2}=0$, then the phase angle becomes zero, and the change in resistance is negligible. As an example, let us compute the maximum capacity which may be present in a Io ooo-ohm coil to to be used on a frequency of 3000 cycles where the allowable uncertainty in the resistance may be I part in IOO ooo, assuming that there is sufficient inductance to make the phase angle zero.

Then

$$
\begin{gathered}
L-\frac{\mathrm{I}}{3} C R^{2}=\mathrm{O} \\
\mathrm{P}^{2} C\left(\frac{\mathrm{I}}{3} L-\frac{2}{\mathrm{I} 5} C R^{2}\right)= \pm \mathrm{IO}^{-5}
\end{gathered}
$$

and

Solving, $C=\mathrm{IO}^{-10}$ farad, or a ten-thousandth of a microfarad. This is a very small capacity, and great care must be taken if such a coil is to be realized. With a Iooo-ohm coil, the allowable capacity is a hundredth of a microfarad, while with a Ioo-ohm coil a microfarad can be tolerated. 
If 100,1000 , and Io $000-0 h m$ coils were to be constructed from wire of the same size and wound in the same manner, then the capacity would increase as rapidly as the resistance, so that the change in resistance of the Iooo-ohm ocil would be nearly Io 000 times as much as the change in resistance of the Ioo-ohm coil, while the Io ooo-ohm coil would change Ioo ooo ooo times as much as the Ioo-ohm coil. If they are constructed of wires of different size, such that with a single layer they will each have the same surface, then a Iooo-ohm coil will change in resistance 400 times as much as a roo-ohm coil, and a Io o00-ohm coil 160000 times as much as the roo-ohm coil. In the above it has been assumed that for the Ioo-ohm coil the phase angle is zero and that the formulas for parallel wires will hold for bifilar coils.

The effect upon phase angle in these cases is also interesting. In the first case, where the wire for the different coils is all of the same size, the capacity, inductance, and resistance all increase directly as the length $l$, so that $L^{\prime}=\left(K-K_{1} l^{3}\right)$, where $K$ and $K_{1}$ are constants. This shows that the term containing capacity increases much more rapidly than the inductance term, so that if a rooohm coil has zero phase angle, a similar Iooo-ohm coil will have a decided negative phase angle, the real inductance being only I per cent of the effective inductance. With the ro ooo-ohm coil this effect is greatly increased, so that the real inductance becomes negligible.

With coils similarly wound, but of different sizes of wire, so that they have the same surface, the inductance and capacity increase in the same ratio as the resistance increases. Hence, while the increase in the phase angle is less rapid, the relative importance of the inductance and capacity terms is the same.

From what is given above, it will be seen that the effect of capacity upon resistance is appreciable only in the case of highvali1ed coils, Iooo ohms and over. The effect of capacity upon phase angle is more marked. In most cases it is the predominating factor in coils of 1000 ohms or over, but it also produces a measurable effect in a ro-ohm coil, and perhaps even in a I-ohm coil. 


\section{(a) EFFECT OF TEMPERATURE UPON THE CAPACITY}

Since in many coils the phase angle is largely dependent upon the capacity, the temperature coefficient of the phase angle will be nearly that of the capacity. For a poor dielectric, such as is generally found in resistance coils, this temperature coefficient of the capacity is usually quite large. In one bifilar coil which had been cut at the middle point it was measured and found to be I per cent per degree. Hence, if sufficient current is used to heat the coil the phase angle will change while the coil is under observation. As the dielectric heats rather slowly when the current begins to pass through a coil, the phase angle will depend upon the length of time which the current has been flowing as well as upon the magnitude of the current.

This drift of the effective inductance has often been observed by us, and before the cause was understood it gave us considerable trouble. The following example will show the magnitude of this for an ordinary coil. A rooo-ohm bifilar coil, suspended in the air, was connected in a circuit through which a current of 50 milliamperes could be sent. Within five minutes after closing the circuit a drift of 5 microhenrys in the effective inductance was observed.

The winding was then cut at its middle point and it was found to have a capacity of $0.0014 \mu \mathrm{f}$ whose temperature coefficient was I per cent per degree. Hence, a rise of I degree in the temperature of the dielectric will explain the change in the effective inductance which was observed.

The effect of the temperature coefficient of the capacity upon the high-frequency resistance would be very small. It is so interconnected with other effects that we have never observed it. In well-designed coils the capacity should be so small that its change with temperature will not produce any noticeable effects.

\section{(b) EFFECT OF HUMIDITY UPON THE CAPACITY}

It has been shown ${ }^{15}$ that the shellac of resistance coils absorbs moisture from the air. On account of the high dielectric constant of water, one would expect that this would affect the effective inductance of the coil as a result of the change in the capacity. This was found to be the case. In one coil the effective induc- 
tance was increased algebraically by 20 per cent by baking at $\mathrm{I} \mathrm{IO}^{\circ} \mathrm{C}$ for $\mathrm{I} 5$ minutes. Also, coils where the insulation is of uncovered silk show large changes of the capacity with humidity. This trouble may be overcome by coating the coil with paraffin or sealing it in a metal case.

\section{EFFECT OF ABSORPTION IN THE DIELECTRIC BETWEEN THE WIRES}

In coils for direct current work the only property required of the insulating material between the turns is that it shall not allow an appreciable leakage between the wires. However, where alternating current is used the absorption of a poor dielectric may produce an apparent leakage between the turns of a coil whose direct current insulation resistance is sufficiently high. If we again consider the coil as equivalent to two parallel wires, the effect of this absorption upon the resistance can be shown to be

$$
R^{\prime}=R\left[\mathrm{I}-\frac{\mathrm{I}}{3} p C R \tan \theta\right]
$$

where $\theta$ is the phase difference of the capacity due to absorption.

The absorption also causes the effective inductance to change with frequency, since the capacity of an absorbing condenser is a function of the frequency. The change in effective inductance is $\left(C_{1}-C_{2}\right) R^{2}$, where $C_{1}$ and $C_{2}$ are the capacities at two frequencies.

The magnitude of these effects can only be determined by experiment. For this purpose the coil which had been opened at the center was again employed. It was a commercial roooohm coil, wound bifilar with silk-covered manganin wire, then shellaced and baked.

The following data were obtained:

\begin{tabular}{llll} 
Frequency of A. C. & \multicolumn{1}{c}{ I00 } & I $500 \sim$ & \multicolumn{1}{c}{$2700 \sim$} \\
Capacity & $0.00160 \mu \mathrm{f}$ & $0.00158 \mu \mathrm{f}$ & $0.00152 \mu \mathrm{f}$ \\
Phase angle & 2.6 & $\mathrm{I}: 5$ & 1.2
\end{tabular}

Having joined the wires at the center again, the following measurements were made:

$\begin{array}{lcccc}\text { Frequency } & \text { Zero } & \text { IOO } & \text { I } 500 \sim & 2700 \sim \\ \text { Resistance (Ohms) } & \text { I0O2.97 } & \text { IOO2.93 } & \text { IOO2.77 } & \text { IOO2.55 } \\ \text { Effective inductance } & 0.54 \mathrm{mh} & 0.54 \mathrm{mh} & 0.50 \mathrm{mh}\end{array}$


From the first set of measurements the change in resistance and inductance can be approximately computed, while the observed values come directly from the second set. These give the following results:

\begin{tabular}{|c|c|c|c|c|}
\hline & & 0 to $100 \sim$ & 0 to $1500 \sim$ & 0 to $2700 \sim$ \\
\hline \multirow{2}{*}{ Change in resistance (Ohms) } & \multirow{2}{*}{ 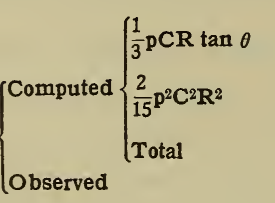 } & $\begin{array}{l}1.4 \times 10^{-5} \\
0.01 \times 10^{-5}\end{array}$ & $\begin{array}{l}12 \times 10^{-3} \\
3 \times 10^{-5}\end{array}$ & $\begin{array}{l}18 \times 10^{-5} \\
8 \times 10^{-5}\end{array}$ \\
\hline & & $\begin{array}{r}1.4 \times 10^{-5} \\
4 \times 10^{-5}\end{array}$ & $\begin{array}{l}15 \times 10^{-5} \\
20 \times 10^{-5}\end{array}$ & $\begin{array}{l}26 \times 10^{-5} \\
42 \times 10^{-5}\end{array}$ \\
\hline & & & $100 \sim$ to $1500 \sim$ & $100 \sim$ to $2700 \sim$ \\
\hline Change in inductance (Henrys & s) $\left\{\begin{array}{l}\text { Computed }\left(C_{1}-C_{2}\right) R^{2} \\
\text { Observed }\end{array}\right.$ & & $\begin{array}{c}2 \times 10^{-5} \\
0\end{array}$ & $\begin{array}{l}8 \times 10^{-5} \\
4 \times 10^{-5}\end{array}$ \\
\hline
\end{tabular}

While these results are not all that could be desired, yet they are probably all that can be reasonably expected, considering the difficulties in such measurements.

The phase difference of the capacity is a characteristic of the dielectric. Therefore, the above values are typical of what may be expected with shellaced coils. Hence, from equation (II), we see that the higher-valued coils will have a larger percentage change in resistance, due to absorption. It is interesting to see how much this will be under the conditions which were assumed in computing the effect of the capacity upon the resistance. For the case where the coils are made of wire of the same size, this decrease in resistance will be proportional to the square of the resistance. Where the coils have the same area, the decrease will be proportional to the four-thirds power of the resistance.

The relative change of capacity with frequency is also a characteristic of the dielectric. Hence, in coils where the capacity is the predominating factor in the effective inductance, the percentage change in phase angle with frequency will be independent of the resistance of the coil. 


\section{CONCLUSIONS FROM THEORETICAL WORK}

(I) It is possible to make a resistance coil in which the phase angle will be small and practically the same for all frequencies. This requires for a bifilar coil that $L=\frac{C R^{2}}{3}$ and that $C$ shall be so small that its change with frequency may be neglected.

(2) The alternating-current resistance of ordinary coils for frequencies up to 3000 cycles, is not affected by the skin effect, but may be decidedly affected by capacity between the turns and by absorption in the dielectric. This can only be overcome by keeping the capacity as low as is consistent with the demands for a small phase angle.

\section{APPLICATIONS}

The preceding investigation shows that it is desirable to have both the inductance and capacity small. This means that the coil shall contain as little wire as possible, besides having the necessary wire put in the most advantageous shape. As all of the heat which is lost from a coil in continuous operation passes through the surface, there is no advantage, as far as carrying capacity is concerned, in making a multiple layer coil. With regard to inductance and capacity effects there is a decided disadvantage. Hence, as far as possible all coils should be single-layer coils.

The area of surface required will depend upon the amount of energy to be expended in the coil and upon the allowable rise of temperature. It seemed desirable to have a surface of approximately $50 \mathrm{~cm}^{2}$, as then an expenditure of $\mathrm{I}$ watt upon a coil immersed in oil will raise its temperature only about $\mathrm{I}$ degree when the coil is wound on a poor conductor of heat. If the coil is in air, the rise in temperature will be nearly ro times as great. Even with a given area, the size of the spool will affect the phase angle as is shown in Fig. 2. However, this effect is small. A spool 2.5 $\mathrm{cm}$ in diameter is a convenient size, and all of the results given are for spools of this size.

The material and treatment of the coils is the same as for directcurrent coils. They are made of silk-covered manganin wire. After winding they are shellaced and baked at $120^{\circ}-130^{\circ} \mathrm{C}$ for several hours. The baking is to anneal the wire as well as to $56109^{\circ}-\mathrm{r} 2-5$ 
dry the shellac. They should be protected from the moisture of the air by dipping in molten paraffin after baking or by sealing in air-tight cases. This protection is necessary to prevent changes in the effective inductance as weil as changes in the resistance.

The collected results of our experiments are given in Table I. In no case is the time constant greater than $5 \times 10^{-8}$ second. Hence, with 3000 cycles the maximum phase angle is $3.5^{\prime}$. The change in resistance with frequency is also negligible in all cases. A brief description of each coil is given in the table and a more detailed description follows.

\section{TABLE I}

Constants of Resistance Coils for Alternating-Current Measurements

\begin{tabular}{|c|c|c|c|c|c|c|c|c|}
\hline \multirow{2}{*}{$\begin{array}{l}\text { Resist- } \\
\text { ance } \\
\text { of coil }\end{array}$} & \multirow{2}{*}{$\begin{array}{l}\text { Material of } \\
\text { spool }\end{array}$} & \multirow{2}{*}{$\begin{array}{l}\text { Shape of } \\
\text { resist- } \\
\text { ance } \\
\text { material }\end{array}$} & \multicolumn{3}{|c|}{$\begin{array}{l}\text { Size of resistance } \\
\text { material }\end{array}$} & \multirow{2}{*}{ Method of winding } & \multirow{2}{*}{$\begin{array}{c}\text { Effective } \\
\text { induc- } \\
\text { tance of } \\
\text { sample } \\
\text { coil }\end{array}$} & \multirow{2}{*}{$\begin{array}{l}\text { Time } \\
\text { constant }\end{array}$} \\
\hline & & & Width & $\begin{array}{l}\text { Thick- } \\
\text { ness }\end{array}$ & $\begin{array}{l}\text { Diam- } \\
\text { eter }\end{array}$ & & & \\
\hline chms & & & $\mathrm{mm}$ & $\mathrm{mm}$ & $\mathrm{mm}$ & & $\begin{array}{l}\text { micro- } \\
\text { henrys }\end{array}$ & seconds \\
\hline $1 \ldots \ldots \ldots$ & $\begin{array}{l}\text { Brass or porce- } \\
\text { lain }\end{array}$ & Strip & 3 to 5 & 0.1 & ...... & Bifilar .... & +0.05 & $5 \times 10^{-8}$ \\
\hline $10 . \ldots \ldots$ & .... do........ & ...do.... & 1 & 0.1 & ...... & .... do ............. & +.2 & $2 \times 10^{-8}$ \\
\hline $10 \ldots \ldots$ & .....do......... & Wire & & & $0.2 \dot{4}$ & $\begin{array}{c}\text { Three } 30-0 \mathrm{hm} \\
\text { bifilar sections } \\
\text { in parallel }\end{array}$ & +.3 & $3 \times 10^{-8}$ \\
\hline $100 \ldots .$. & .....do........ & ...do... & & ...... & .24 & Bifilar & -1.6 & $1.6 \times 10^{-2}$ \\
\hline $1000 \ldots .$. & Porcelain ..... & ...do.... & & & .10 & $\begin{array}{l}\text { Five } \quad 200-\text { ohm } \\
\text { bifilar sections } \\
\text { in series }\end{array}$ & -16 & $1.6 \times 10^{-8}$ \\
\hline $5000 \ldots$ & .....do... & ...do.. & & & .05 & $\begin{array}{l}\text { Inductive for } 20 \\
\text { turns, then re- } \\
\text { vers ed for } 20 \\
\text { turns, etc. }\end{array}$ & +210 & $2.1 \times 10^{-8}$ \\
\hline $5000 \ldots .$. & .....do... & ...do... & & & .05 & $\begin{array}{l}\text { Inductive, re- } \\
\text { versed each turn }\end{array}$ & +30 & $0.6 \times 10^{-8}$ \\
\hline $10000 \ldots$ & ...... do.. & ...do... & & & .05 & .....do .............. & +100 & $1 \times 10^{-8}$ \\
\hline
\end{tabular}

Each coil is made of manganin wound on spools $2.5 \mathrm{~cm}$ in diameter. With the exception of the coils made of strip, all coils are single layer. Coils are shellaced and baked in the usual manner, then paraffined or sealed. 


\section{HUNDRED-OHM COILS}

A large number of measurements extending over a period of several years have shown that a Ioo-ohm coil usually has a small phase angle. It was natural, therefore, first, to see what was the smallest value of the effective inductance which could be attained with coils of this value, and to see how nearly two coils made in the same manner would agree. An ordinary bifilar winding was used and found to be satisfactory. Two coils made as nearly alike as possible differed in effective inductance by I microhenry, one having -1.6 microhenrys and the other -0.6 microhenry. This gives a difference in phase angle between the two coils of $4 \mathrm{O}^{\prime \prime}$ at 3000 cycles, or less than $I^{\prime \prime}$ at 60 cycles. There was no appreciable difference between coils wound on brass and on porcelain.

A computation of the inductance of such a coil by Rosa's formula ${ }^{16}$ for a "noninductive" winding gives a value of 1.6 microhenrys. Hence, if the coil has an effective inductance of - r.6 microhenrys, it must have a capacity of $3.2 \times \mathrm{IO}^{-4}$ microfarads. The effect of this capacity upon the resistance is less than I part in ro 000 ooo. If properly treated, the effective inductance at any frequency can be depended upon to remain constant to 0.1 or 0.2 microhenry. The data given in Sec. III-3 show a change in capacity between 100 and 3000 cycles of 5 per cent. Other measurements show that the change is rarely twice this in the case of shellaced coils. If the capacity of a Ioo-ohm coil were $3 \times \mathrm{IO}^{-4}$ microfarad, as estimated above, this would cause a maximum change in effective inductance of 0.3 microhenry in the range of frequencies mentioned. Measured values are not much different from this.

\section{TEN-OHM COILS}

With Io-ohm coils, the effect upon the resistance due to the capacity and absorption between the turns of the winding is negligible. Even the $C R^{2}$ term in the effective inductance is small in most cases. Hence, in the design of a ro-ohm coil the important point is to keep the inductance as small as possible.

Two methods of effecting this result have been tried. One is to make the coil of strip manganin, and the other is to use three 
3o-ohm coils in parallel. While the first method gave somewhat better results, the difference in general is not of sufficient importance to justify the additional trouble of making a coil of strip manganin.

The 30-ohm coils were wound of the same size wire as was used upon the Ioo-ohm coil just described. They were wound bifilar in the ordinary manner, the three coils being wound upon the same spool. Whether the spool is of brass or porcelain is of little importance, as practically all the capacity is between adjacent wires. Still, better results could doubtless have been obtained by using wire of smaller diameter, and making five 5o-ohm coils in parallel. This was not considered necessary.

The strip coil was made of manganin o.I $\mathrm{mm}$ in thickness, the width of the strip being I mm. Between the strips of the bifilar winding was placed a layer of silk $0.09 \mathrm{~mm}$ in thickness. This brings the strips close together, making the inductance small and at the same time making the capacity larger than would be the case with round wires of the same cross-sectional area. If a thinner insulator, such as mica, be used, the effective inductance could be made still less.

One of the chief difficulties in winding a strip coil is in keeping the outer strip exactly over the inner strip. This can be largely overcome by binding the two strips rather loosely together with silk thread before winding them into a coil.

\section{ONE-OHM COILS}

In these coils all capacity effects are negligible. Hence, the only thing to consider is the reduction of the inductance to a minimum.

There seems to be no satisfactory method except to use the resistance material in the form of a strip. It is generally considered inadvisable to use manganin thinner than o.I $\mathrm{mm}$. With this material, winding it with a double thickness as is necessary in a strip coil, the strip must be about $5 \mathrm{~mm}$ wide in order to give a surface of $50 \mathrm{~cm}^{2}$. However, as this coil can be wound on a metal spool, so large a surface is not necessary, and a 3 -mm strip is satisfactory for most purposes. Using silk insulation of approx- 
imately $0.09 \mathrm{~mm}$ thickness the effective inductance was o. I microhenry, but with a thin mica insulation this was reduced to 0.05 microhenry.

\section{TENTH-OHM COILS}

It is shown in Table II that in many resistance boxes each tenth-ohm coil has an inductance comparable with that of a I-ohm coil. Hence, in construction of resistance boxes the design of coils of this value should not be neglected.

The best method is to use o.I mm manganin strip, making the width about $3 \mathrm{~mm}$ and the length $\mathrm{ro} \mathrm{cm}$. This is folded in the center and bound together with a thin insulation between. In general, no support will be required. The current-carrying capacity of these is no larger than that of the $\mathrm{i}-\mathrm{ohm}$ coils. The inductance, however, is only one-tenth that of the I-ohm coil, and where these coils are to be used in series with other coils of higher denomination this advantage is more important than that of a large carrying capacity. .

\section{THOUSAND-OHM COILS}

With coils of Iooo ohms the problem is quite different from that met with in the coils just described. As fine wire is used in their construction, the inductance of a bifilar winding becomes relatively small, while the capacity effect increases very decidedly. A method which has often been used is to connect several coils of smaller value in series. In order to obtain data in regard to the correct size of wire, and the proper resistance in each section to make the effective inductance zero, five coils were constructed in which these factors were systematically varied. At the same time two other coils were constructed in order to determine the effect of the size of the spool. The results of these experiments are shown in the curves of Fig. 2. From a study of these curves it was decided that with o.Io-mm wire (a convenjent size for a rooo-ohm coil) a 200-ohm section would have a very small effective inductance. This proved to be the case and a coil was constructed of five $200-0 h m$ sections in series.

In this case it is important that the coil should be wound upon an insulating spool, or that each section be wound upon a metal 


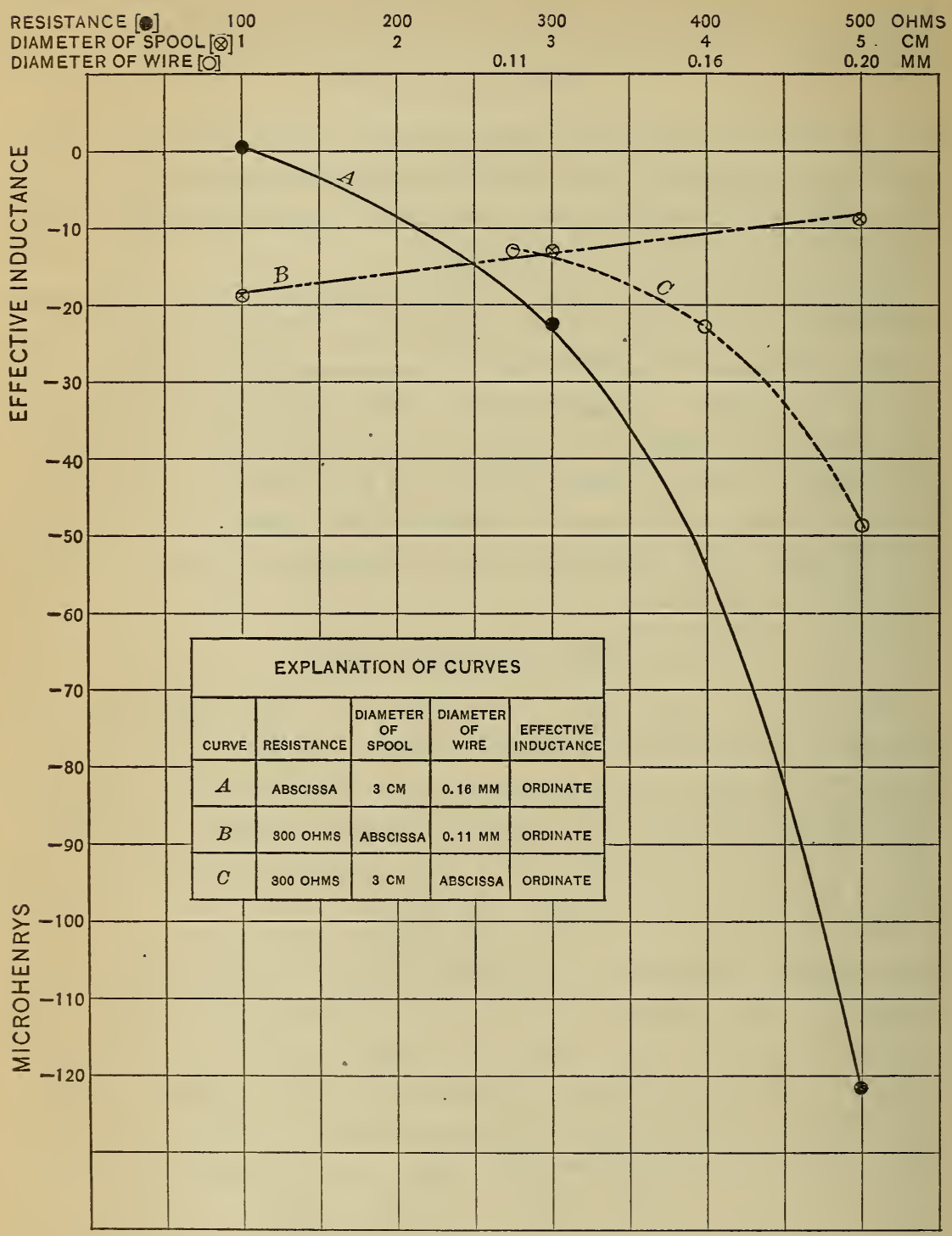

Fig. 2.-Curves Showing the Variation of the Effective Inductance of a Bifilar Coil when the Resistance, Diameter of Spool, and Diameter of Wire are Varied 
spool, and the spools insulated from one another. The necessity for this method of construction is caused by the fact that, if all the sections are upon one metal spool, the capacity between the sections is greatly increased, so that the effective inductance of the sum of five sections will not be five times that of a single section. The importance of this is shown by the following data:

Five times the inductance of a 200-ohm coil... . - I.5 microhenrys

Inductance of five 200-ohm coils in series $\left\{\begin{array}{r}(a) \text { on porcelain ....... } \\ -12 \text { microhenrys } \\ \text { (b) on brass } \ldots \ldots \ldots \\ -74 . \text { microhenrys }\end{array}\right.$

From these measurements it appears that the capacity between sections influences the phase angle even when the sections are wound upon an insulating spool. However, the capacity is nearly seven times as large when the sections are wound on a brass spool, as is shown by the fact that the effective inductance has a much larger negative value in the latter case.

Two coils were constructed according to these specifications, one being wound on a porcelain spool, and each section of the other on a brass spool, the latter spools being insulated by fiber washers on a fiber tube. The first had an effective inductance of $-\mathrm{r} 6$ microhenrys, and the second -9 microhenrys. If we take the larger value of the effective inductance and, assuming it is all due to capacity, compute the effect of this capacity upon the resistance when the frequency is 3000 cycles, we find that the change in resistance is not more than I part in ro 000 ooo. The effect of absorption is larger, but using the most probable phase differences of the capacity, it will not exceed 2 or 3 parts in I 000000 . This makes it very probable that the change of resistance is negligible. We have also failed to detect any change experimentally.

\section{FIVE-THOUSAND-OHM COILS}

As the difficulties in designing coils for alternating-current work increases rapidly above $1000 \mathrm{ohms}$, it seemed desirable first to construct a 5000-ohm coil instead of attempting immediately to construct a ro ooo-ohm coil. The capacity here becomes the important factor, and questions of inductance can be largely neglected. 
At this point it seemed desirable to give up the bifilar winding, and wind an ordinary inductive winding, reversing the direction of winding every few turns. Two such coils were constructed, one with 20 turns before reversing and the other with 50 turns. These coils gave fairly satisfactory results. The change in resistance from o to I 200 cycles was less than I part in 100 ooo (the limit of the sensitiveness of the bridge). The effective inductance of the coil with 20 turns per section was found to be +2 ro microhenrys, while the one having 50 turns per section was +330 microhenrys. For most purposes these may be regarded as satisfactory coils.

However, as the inductance predominates, it was evident that a still better coil could be made by reversing the direction of winding oftener. This was done by a method suggested by Mr. Joseph Ludewig, of the instrument shop of the Bureau. A cylinder of biscuit porcelain $2.8 \mathrm{~cm}$ in diameter and $15 \mathrm{~cm}$ long was obtained. This is porcelain which has received only a preliminary baking and is sufficiently soft to be worked with a steel tool. A narrow slit was cut along one diameter for two-thirds of its length. The cylinder was then baked to increase its strength. This

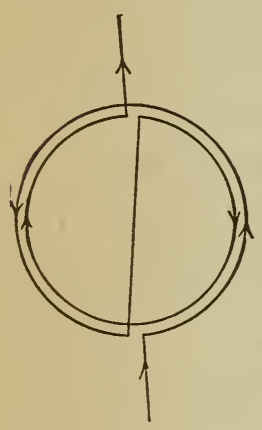

Fig. 3.-Diagram to

Show Method of

Winding Resistance

Coils to Have Small

Inductance and Small Capacity reduced the diameter to about $2.7 \mathrm{~cm}$. The coil was then wound with $0.05-\mathrm{mm}$ manganin wire in the following manner: The wire goes once around the spool, then passes through the slit and one turn is made in the opposite direction, then the wire passed through the slit and one turn made in same direction as the first. The process is repeated until the desired amount of wire has been wound on the spool. This method of winding is shown diagrammatically for two turns in Fig. 3 .

It will be noticed that each turn has two adjacent turns in which the current flows in the opposite direction. This is equivalent to reversing every turn and it means that the inductance will be as small as with a bifilar winding, while the capacity effect will also be small since there is only a small potential difference between 
adjacent wires. The coil constructed according to this method had an inductance of only +30 microhenrys, which was about the limit of measurement.

This method of winding a coil is rather difficult, but it can be done more rapidly than would seem possible at first sight. It gives a very satisfactory coil.

\section{TEN-THOUSAND-OHM COILS}

The method of winding just described was so satisfactory in the case of 5000-ohm coils that it was applied to the construction of a ro ooo-ohm coil. The same size of wire $(0.05 \mathrm{~mm})$ and the same size of spool $(2.7 \mathrm{~cm})$ were employed. This made a.winding about $7.5 \mathrm{~cm}$ long. In.order to leave the porcelain tube sufficiently strong, it was not desirable to cut the slit for more than three-fourths of its length. Hence a tube ro $\mathrm{cm}$ long was required, since the portion which is not slit could not be used for the winding.

The results were very satisfactory. The effective inductance was too small to be accurately measured. It is not more than t 100 microhenrys.

The chief objection to this coil is the difficulty of winding it. Experience has shown that an apprentice can wind a Io ooo-ohm coil in a day. Thus the cost is greater than for ordinary commercial coils, but is not excessive.

\section{COMPARISON OF NEW COILS WITH ORDINARY NONINDUCTIVE COILS}

The relative merits of the new coils are shown in Table II, in which the values of the effective inductance and of the change in resistance from o to $\mathrm{I} 200$ of the new coils and of a representative coil from resistance boxes by German and American manufacturers are given. No attempt has been made to make the table complete, but sufficient results are given to show the improvements which have been effected. 


\section{TABLE II}

\begin{tabular}{|c|c|c|c|c|c|c|}
\hline \multirow{2}{*}{$\begin{array}{l}\text { Nominal } \\
\text { resistance } \\
\text { of coil }\end{array}$} & \multicolumn{3}{|c|}{ Effective inductance in microhenrys at $1200 \sim$} & \multicolumn{3}{|c|}{ Change in resistance, 0 to $1200 \sim$} \\
\hline & New coil & A & G & New & A & G \\
\hline 0.1 & +0.005 & +0.14 & 0.18 & & & \\
\hline 1 & +0.05 & +0.4 & 0.5 & & & \\
\hline 10 & +0.3 & +0.9 & + & & & \\
\hline 100 & -1.6 & -5 & - & & & \\
\hline 1000 & -16 & -400 & 100 & $<0.001 \%$ & $-0.08 \%$ & $-0.05 \%$ \\
\hline 5000 & +30 & & -27500 & $<0.001$ & & -0.2 \\
\hline 10000 & +100 & & -100000 & $<0.001$ & & -1 \\
\hline
\end{tabular}

A form of resistance proposed by Rowland ${ }^{17}$ is quite satisfactory for high resistance alternating current work: It consists of fine wire wound inductively on thin sheets or cards of mica. The effective inductance of resistances of this type is small, the time constant being seldom more than $1^{-6}$ and often as small as $10^{-7}$ second. However, such resistances have considerable surface, so that the capacity between two cards which are connected in series may appreciably affect the phase angle. The magnitude of the capacity $C$ can be approximately computed by assuming that the cards are plates of a condenser. The effect of the capacity upon the effective inductance was found by experiment to be approximately $-1 / 3 C R^{2}$, where $R$ is the resistance of the two cards. While this type of resistance has been extensively used in multipliers for voltmeters and wattmeters, it has not found extensive use in resistance boxes.

A type of resistance which accomplishes the same results as the above is due to Duddell and Mather. ${ }^{18}$ It consists of a fine wire woven as the woof in a silk warp. While no recent measurements have been made in this laboratory on such resistances, yet it is evident that satisfactory results may be obtained by this method.

\section{METHODS OF CONNECTING COILS IN BOXES}

The best method of connecting the coils in a box will depend on the resistance of the coils. For low resistances (up to roo ohms) 
the connections should be so arranged that the inductance is small. For high resistances (I000 ohms and over) the inductance of the leads is of little importance, but "the capacity between the leads, between the leads and the coils, and between the coils themselves becomes of importance.

For low-resistance coils, the method in common use at present suffices for most purposes. To the terminal block is soldered a copper rod which extends below the bottom of the coils when they are fastened in place. To the lower end of this is attached one terminal of each of the two adjacent coils. If the effective inductance of each coil is measured from the terminals on the top of the box, then the inductance of the terminal rods will be included in each measurement, while in the ordinary use of the box there will never be more than two rods in the circuit. To show this effect, the inductance of each of the ten I-ohm coils of a decade box was measured by connecting to the terminals on the top of the box. The Io were then measured in series. The sum of the inductances of the Io coils was 0.57 microhenry larger than the inductance of the Io in series. This shows the inductance of each rod to be 0.03 microhenry.

This could be slightly reduced by making the rods of larger diameter so as to diminish the self-inductance. Another method is to use two rods from each terminal block and to connect only one coil to a rod. There will then be the mutual inductance between the two rods from one block when two coils are used in series. This will be smaller than the self-inductance, so that the inductance of a group of coils in series will more nearly equal the sum of the inductances of the individual coils. However, it will not often be necessary to use this refinement.

For high-resistance coils, the capacity effects must be closely guarded against, while on the other hand, the inductance of the leads is negligible. With coils connected as described above for low-resistance coils, the capacity between the terminal blocks of the coils forms a shunt on the impedance of the coil.' In this case, however, the capacity is always a shunt on the coil and produces the same effect whether the coil is measured from its terminals or is in series with other coils. Although this capacity is small, it 
can not always be neglected. In one of the dial decade boxes in this laboratory it amounts to about $5 \times \mathrm{ro}^{-6} \mu \mathrm{f}$. This would change the effective inductance of a rooo-ohm coil by 5 microhenrys (an amount which is sometimes of importance), and the effective inductance of a Io ooo-ohm coil would be changed by 0.5 millihenry. The effective resistance at 3000 cycles is not altered by more than I part in I 000000 in either case. It is evidently desirable that the terminal blocks of high-resistance coils should be small, and as far apart as is consistent with good operation.

The capacity between the coils themselves also measurably affects the phase angle of the coils when they are joined in series. With two rooo-ohm coils it was found that the effective inductance was decreased algebraically by 4 microhenrys when their distance apart was changed from $20 \mathrm{~cm}$ to $2 \mathrm{~mm}$. With two 5000-ohm coils the effective inductance was decreased algebraically 200 microhenrys by bringing close together coils which nad been separated by a distance of $10 \mathrm{~cm}$.

Perhaps a more troublesome factor is what is sometimes called the "dead end effect." When only a part of a resistance box is being used, the remainder of the coils are connected to the circuit, and their capacity to the other coils as well as to earth may produce an appreciable effect. To minimize this, the resistance box should be so constructed that each coil is entirely disconnected from the others when not in the circuit. No satisfactory design of a resistance box which accomplishes this is known to the authors.

The position of the terminals of the box is sometimes of importance. If only a small resistance is to be used from the box and it is desired to keep the inductance of the circuit low, a twisted cord should be used for leads. In this case the terminals should be near each other. If, on the other hand, a large resistance is to be used, then it is more important to decrease the capacity between the leads than to decrease their inductance. In this case the leads, and hence the terminals, should be as far apart as possible. In the case of boxes designed for general use, a mean value should be chosen. If the terminals are from 5 to Io $\mathrm{cm}$ apart, they will meet all ordinary requirements. 


\section{SUMMARY}

I. A theoretical discussion is given to show the conditions which must be fulfilled in the construction of resistance coils in order that the phase angle shall be small and the change of resistance with frequency negligible.

2. These principles are applied to the design of coils of different denominations, and specifications are given for the construction of coils of different denominations from o.I to ro ooo ohms.

3. There is given the results of measurements on sample coils of each denomination, constructed according to these specifications.

4. A comparison is made between the constants of these coils and those of commercial coils.

5. Suggestions are made as to the method of connecting coils when they are to be used in resistance boxes.

WASHINGTON, September I, I9I I. 